\title{
APPLICATION OF ARTIFICIAL NEURAL NETWORKS TO HEIGHT TRANSFORMATION
}

\author{
Mustafa Yilmaz, Bayram Turgut, Mevlut Gullu, Ibrahim Yilmaz
}

Original scientific paper The vertical positioning has two indispensable constituents: the height and the relevant reference surface. The definition of the height differs according to the appointed reference surface. Global Navigation Satellite Systems (GNSS) ensure ellipsoidal heights relative to a geodetic reference ellipsoid surface. However, many field applications require heights that are related to a physically meaningful surface (e.g. the geoid). Such physically meaningful heights often provided in terms of orthometric heights. The geoid undulation is the relation between the ellipsoidal and orthometric heights. The ellipsoidal heights can be transformed to orthometric heights via two principal approaches: a gravimetric geoid model, and geometrical interpolation between geoid undulations where GNSS observations have been collocated with benchmarks. The purpose of this study is investigating the applicability of a back propagation artificial neural network as a height transformation tool.

Keywords: back propagation artificial neural networks; ellipsoidal height; orthometric height

Primjena umjetnih neuronskih mreža na transformaciju visine

Izvorni znanstveni članak

Dvije su osnovne komponente vertikalnog pozicioniranja: visina i odgovarajuća referentna površina. Definicija visine se mijenja u skladu s odabranom referentnom površinom. Satelitski sustavi globalne navigacije (Global Navigation Satellite Systems - GNSS) daju elipsoidne visine razmjerne površini geodetski referentnog elipsoida. Međutim, mnoge aplikacije zahtijevaju visine koje su povezane s fizikalno značajnom površinom kao što je geoid. Takve visine su u obliku ortometrijskih (ili normalnih) visina. Veza između elipsoidnih i ortometrijskih visina je visina geoida iznad referentnog elipsoida, obično nazivana valovitim kretanjem geoida. Dva su osnovna pristupa kod pretvaranja elipsoidnih u ortometrijske visine: gravimetrijski model geoida i interpolacija između geometrijski deriviranih valovitih kretanja geoida gdje su GNSS mjerenja locirana uz nivelacijske točke. U ovom se radu istražuje korisnost umjetnih neuronskih mreža s unatražnim rasprostiranjem kao alternativni alat za transformaciju visine.

Ključne riječi: elipsoidna visina; ortometrijska visina; umjetne neuronske mreže s unatražnim rasprostiranjem

\section{Introduction}

The geodesy is defined by Helmert [1] as 'the science of the measurement and mapping the Earth's surface'. Mainly as a consequence of space-based technological developments allowing us to identify the Earth system parameters in a globally consistent and highly accurate three-dimensional (3D) reference frame, the scope of geodesy has been evolving beyond Helmert's concept. Today, geodesy is the scientific discipline that deals with the determination and representation of the Earth's geometry, gravity field, and rotation in a 3D time-varying space. The first pillar of this characterization of geodesy remarks to determining the Earth's size and geometric shape with the utmost precision. The geometry of the Earth deals with the determination and the presentation of precise $3 \mathrm{D}$ object positions by establishing the geodetic reference networks [2]. A spatial position on the surface of the Earth is described by determining 3D-coordinates of the point of interest with respect to the centre of the Earth, the equator, and the prime meridian. Conventionally, the 3D position of a point was separated into two components: horizontal coordinates and vertical positioning. The horizontal coordinates are beyond the scope of this paper, so the determination of these coordinates will not be mentioned here. The purpose of this study is to deal with the height transformation problem for the vertical positioning.

Most of the geodetic, cartographic, surveying, oceanographic and engineering applications require vertical positioning. The vertical positioning has two indispensable constituents: the height, and the relevant reference (datum) surface. The definition of the height differs according to the appointed reference surface. The surface of the Earth with its topography has irregularities (caused by the variations in rock density, mountain ranges, and ocean trenches is) to be a convenient reference surface for the computing vertical position. Hence, two reference surfaces are defined for most practical purposes: the ellipsoid, a geometrical reference surface, and the equipotential surface most close approximated by mean sea level (MSL) called the geoid. Hereby, two types of height are recognised: ellipsoidal height referenced to an ellipsoid and gravity-related height (elevation) referenced to the geoid.

Traditionally, the practical heights of the points on the surface of the Earth are obtained by combining geometric levelling aka spirit levelling and gravity observations. The heights are determined, along the local plumb-line direction, from MSL at points. By its nature, this technique is precise, but on the other hand, labourintensive and time consuming.

Nowadays, with the advent of space-based techniques, Global Navigation Satellite Systems (GNSS) has become the leading positioning tool in geodetic and surveying applications. GNSS yields ellipsoidal heights related to the a geodetic reference ellipsoid surface. These are geodetic heights which are purely geometrical quantities. However, many field applications require heights that are related to a physically meaningful surface (e.g. the geoid). Such physically meaningful heights often ensured in terms of orthometric heights.

The extensive use of GNSS in practical geodetic applications for height determination and to replace expensive levelling measurements has incited the need of a height transformation. The proper implementation of height transformation has been one of the essential tasks in many engineering, surveying, mapping, and geodetical 
applications in the last few decades. The height of the geoid above the reference ellipsoid is the relation between the ellipsoidal and orthometric heights, and it is usually called the geoid undulation (geoidal height) (Fig. 1). Thus, the knowledge of the geoid is the practicable parameter for the transformation process between the ellipsoidal and orthometric height systems [3].

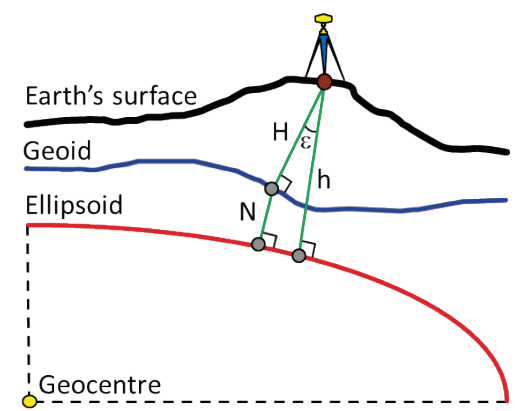

Figure 1 The relationship between the height systems

The fundamental relationship between ellipsoidal heights $(h)$ acquired from GNSS observations and orthometric heights $(H)$ related to the geoid obtained from geometric levelling and gravity data is defined by [4]:

$h-H-N=0$

where $N$ represents the geoid undulation. Eq. (1) is not exact due to the ignorance of the vertical deflection $(\varepsilon)$. Nonetheless, Eq. (1) is appropriate for most practical applications, because $\varepsilon$ has a negligible influence (sub mm-order) on the orthometric height $[5,6,7]$. The ellipsoidal heights can be transformed to the orthometric heights through simple manipulation of Eq. (1) if the geoid undulation is known.

In Turkey, Large Scale Map and Map Information Production Regulation (LSMMIPR) has proposed two approaches for the transformation between ellipsoidal heights and orthometric heights: the utilize of the existing national geoid model by including GNSS/Levelling points and a local geoid modelling based on GNSS/Levelling data that can be used for the geometrical interpolation between geoid undulations where GNSS measurements have been collocated with benchmarks [8].

There are many interpolation methods for geoid undulations in order to transform ellipsoidal heights to orthometric heights, but polynomial interpolation has usually been employed for height transformation [9, 10, $11,12]$. In diversified fields of engineering, the artificial neural network (ANN) has been utilized. ANN applications in geodetic, cartographic, and surveying applications have increased in the last decade and remarkable accomplishments were obtained through ANNs such as: deformation analysis [13], outlier detection in geodetic networks [14], ambiguity resolution for GNSS [15], coordinate-datum transformation [16, 17], local geoid modelling [18], georeferencing of historical maps [19], prediction of the Earth orientation parameters [20], geodetic velocity estimation [21].

The purpose of this study is to investigate the application of ANN (by obtaining the best model configuration) as a height transformation tool in order to convert ellipsoidal heights to orthometric heights. There are varying kinds of neural networks. Back propagation artificial neural networks (BPANN) is selected as the height transformation method in this study. The polynomial interpolation method is also used for transforming ellipsoidal heights to orthometric heights in order to evaluate the fulfilment of BPANN. The root mean square error (RMSE) values are utilized to compare the results over a test area.

\section{Theoretical concepts}

For this study, BPANN (supervised learning and feed-forward) was used in ANN approach. In the interpolation approach, a commonly applied method, $3^{\text {rd }}$-degree (cubic) polynomial was used. The theoretical information about the used methods are given in the following sections.

\subsection{Artificial neural networks}

ANN is a computational method based on a simplified model based on learning, commentating and decision-making tasks executed in human brain. ANN is structured through layers of interconnected artificial neurons transforming the input data into corresponding output data. ANNs have been implemented to several functions such as modelling, estimation, classification, prediction, optimisation, and filtering owing to their significant advantages (i.e., tolerance and applicability to noisy and complex data, non-parametric nature, optional decision making skills and incorporation of various types of data) [22]. The geodetic applications assume that, the data have been normally distributed. However, in real-life problems this presumption is not practical as dataset might have skewed distribution. Between input and output spatial data, ANNs can supply non-linear mapping by its non-parametric essence which requires no apriori knowledge about the data frequency and distribution. Therefore, ANN has a unique superiority over the conventional prediction techniques (i.e. interpolation methods) [21].

\subsubsection{Back propagation artificial neural networks}

BPANN [23] is an effectual multilayer perceptron (MLP) model through its flexibility and simple implementation. BPANN architecture is composed of (i) an input layer ( $K$ neurons characterizing input variables), (ii) one or more hidden layers ( $q$ neurons capturing the nonlinearity of the data), and (iii) an output layer ( $n$ neurons characterizing the dependent output variables) (Fig. 2). All neurons have been connected by weights adjusted by an iterative training procedure known as back propagation algorithm. After the training process, all neurons are operated by an activation function for generating the output data within a permitted amplitude range [24]. BPANN output $(n=1)$ can be defined by:

$$
y=f\left(\sum_{j=1}^{q} W_{j} f\left(\sum_{l=1}^{K} w_{j, l} x_{l}+w_{j, 0}\right)+W_{0}\right)
$$


where $W_{j}$ is the weight between the $j^{\text {th }}$ hidden neuron and the output neuron, $w_{j, l}$ is the weight between the $l^{\text {th }}$ input neuron and the $j^{\text {th }}$ hidden neuron, $x_{l}$ is the $l^{\text {th }}$ input parameter, $w_{j, 0}$ is the weight between a fixed input (equal to 1 ) and $j^{\text {th }}$ hidden neuron and $W_{o}$ is the weight between a fixed (input equal to 1) and the output neuron [25].

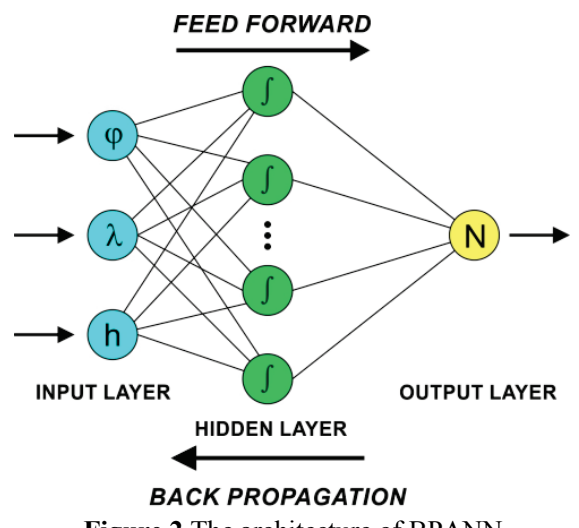

Figure 2 The architecture of BPANN

For hidden layer and output layer, the sigmoid function is used, expressed by [26]:

$f(z)=1 /\left(1+e^{-z}\right)$

where $z$ is the input information of the neuron. The values of BPANN inputs and outputs have to be scaled in the range of $f(z) \in[0,1]$.

The training process (back-propagation) adjusts the weights between the hidden and the output layers. This iterative procedure is based on squared error minimization (delta rule) by updating the weights for decreasing the residuals of BPANN output.

\subsubsection{BPANN design and optimisation}

The best model design that captures the functional relationship generalizing the multidimensional inputoutput mapping problems is researched during the construction and optimisation of ANNs. The development and optimisation approach of Yilmaz and Gullu [21] is followed while structuring BPANN. The detailed information can be found in the related reference. The parameters of BPANN of this study are given in Tab. 1.

\begin{tabular}{ll}
\multicolumn{2}{c}{ Table 1 BPANN's design - optimization parameters } \\
\hline \multicolumn{1}{c}{ Parameters } & \multicolumn{1}{c}{ Settings } \\
\hline Training process & Gradient descent \\
Activation function & Sigmoid \\
Input-Hidden-Output neurons & $3-18-1$ \\
Early stopping & Validation data set \\
Preprocessing of data & Min-max normalization \\
Initial weight range & {$[-0,25 ; 0,25]$} \\
Learning rate (LR) & 0,3 \\
LR decrease & 0,5 \\
LR increase & 1,05 \\
Momentum term & 0,6 \\
Performance indicator & Mean square error
\end{tabular}

\subsection{Polynomial interpolation}

Polynomial interpolation is one of the most frequent and effective mathematical models in surface approximation. Furthermore, polynomial interpolation is widely used is used for trend surface analysis. The study area is expressed by a single function. The general expression of a $m$-degree polynomial interpolation may be given as:

$$
H(y, x)=\sum_{i=0}^{m} \sum_{j=0}^{m-i} a_{i j} y^{i} x^{j}
$$

where $H(y, x)$ denotes the height information of the point with known horizontal coordinates $(y, x)$ and $a_{i j}$ includes the unknown polynomial coefficients $(i, j=0, \ldots, m)$. The degree of the polynomial should be determined depending upon the topography and the size of the test area. With the use of Eq. (4), $a_{i j}$ is determined by least-squares adjustment (LSA) method [27].

\section{Test area, data acquisition, evaluation methodology}

The height transformation is fulfilled over a test area located in central-western regions of Turkey. The geographical boundaries of the test area are: $37,32^{\circ} \leq \varphi \leq 40,44^{\circ} \mathrm{N} ; 28,48^{\circ} \leq \lambda \leq 32,71^{\circ} \mathrm{E}$. The test area is approximately defining an area of $120400 \mathrm{~km}^{2}$ $(\sim 346 \mathrm{~km} \times \sim 348 \mathrm{~km})$.

The height transformation procedure utilizes a source data set in the test area that consists of 87 control points belonging to Turkish National Fundamental GPS Network (TNFGN) that has been established through surveys between 1997 and 1999. 3D coordinates and their associated velocities of each station were computed in ITRF-2000 with periodic GPS measurements and transformed into ITRF-96 that is the initial reference frame of TNFGN. The spatial accuracies of the TNFGN stations are within the range of $1 \div 3 \mathrm{~cm}$, whereas the relative accuracies are about $0,01 \div 0,1 \mathrm{ppm}$. Besides, TNFGN has been linked to Turkish Horizontal and Vertical Control Networks through overlapping stations [28]. Turkish National Vertical Control Network (TNVCN) has been realized by the adjustment of geopotential numbers at 26000 benchmarks. Almost $30000 \mathrm{~km}$ geometric levelling between $1935 \div 1999$ periods were supplemented by surface gravity data along the. The geopotential numbers were divided by gravity value (taken along the plumb-line) in order to express them in the form of orthometric heights. Wherefore, a pure orthometric height cannot be practically realized, the Helmert orthometric heights approximation has been used for TNVCN [29].

The source dataset ( 87 TNFGN points with known ellipsoidal and orthometric heights) is separated into three sub-sets as: reference (50 points for the training/ modelling procedure), validation (20 points for the controlling procedure), and test (17 points for the external accuracy rating). The statistics of reference, validation, and test datasets are given in Tab. 2, and the geographical distribution of source data points within the test area is shown in Fig. 3. 
Table 2 The statistical values of the datasets (units in $\mathrm{m}$ )

\begin{tabular}{lccc}
\hline & Training & Validation & Test \\
\hline Minimum & 33,492 & 34,948 & 32,120 \\
Maximum & 38,927 & 38,791 & 38,772 \\
Mean & 37,008 & 37,394 & 36,699 \\
Std. Dev. & 1,229 & 0,973 & 1,829 \\
\hline
\end{tabular}

The reference points are covering the test area from outside. The validation points are selected to compose an interpolation task and the test points are selected to compose an extrapolation task considering the geodetic network constituted by the reference dataset. The separation is done in regard to that each dataset should be representative of all possible variations of the source dataset.

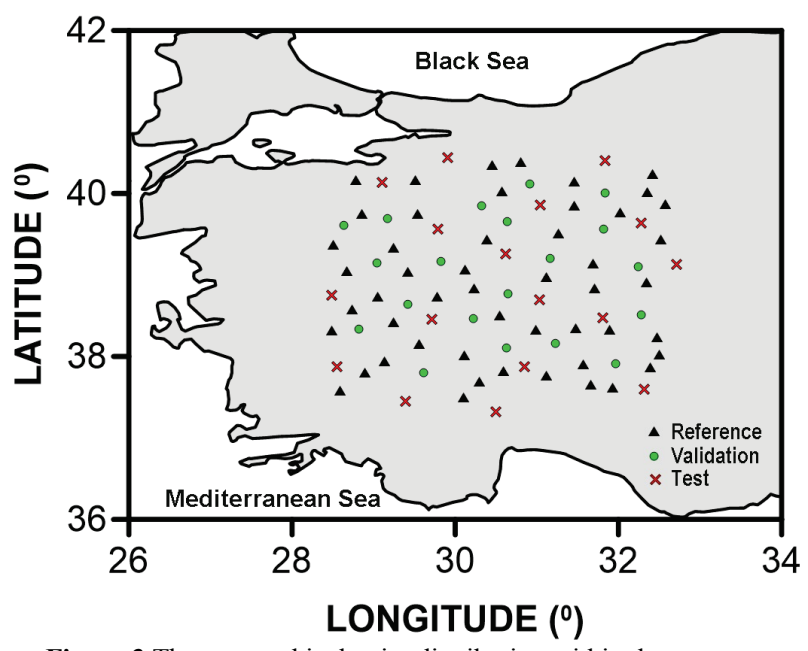

Figure 3 The geographical point distribution within the test area

The reference points are covering the test area from outside. The validation points are selected to compose an interpolation task and the test points are selected to compose an extrapolation task considering the geodetic network constituted by the reference dataset. The separation is done by keeping in mind that each dataset should be representative of all possible variations of the source dataset.

The evaluation of the height transformation is focused on the discrepancies between the known geoid undulation (from Eq. (1)) and the geoid undulation calculated by BPANN and polynomial interpolation using the equation below:

$$
\Delta N=N_{\text {known }}-N_{\text {calculated }}
$$

For the statistical analysis of geoid undulation discrepancies, minimum, maximum, and mean values were inquired by RMSE values due to: their sensitivity to small errors to evaluate the deviations between known and calculated geoid undulations [30], acting as global measures for comparing interpolation techniques [31], efficient tools for evaluating the results of ANN applications [32]. RMSE is defined by:

$$
R M S E=\sqrt{\frac{1}{n} \sum_{i=1}^{n}\left(\Delta N_{i}\right)^{2}}
$$

where $n$ represents the number of validation/test points.

\section{Experimental study}

In ANN approach, BPANN is trained by the reference points, and the performance of BPANN is evaluated by the validation points. The geoid surface model of the test area is generated by the reference points, and the estimation accuracy of polynomial interpolation is checked by the validation points in the polynomial interpolation approach. The test points are used as the external data set in order to assess the accuracies of the two approaches.

For the experimental study, BPANN is proposed as three (input-hidden-output) layered. The geographical coordinates $(\varphi, \lambda)$ and ellipsoidal height $(h)$ of the point are selected as input variables, and the geoid undulation $(N)$ of the point is used as output variable for training and validation procedure of BPANN. A constructive trial and error method was used for determining the optimal number of the hidden neurons of BPANN. The training process was started with 2 hidden neurons and BPANN is fed by gradually increasing the hidden neurons. Consequently, the optimal number of hidden neurons was specified as 18 for BPANN that presented the smallest network error. Thus, the optimum BPANN architecture was defined as [3:18:1] from a MATLAB-ANN module that is allowed to change the BPANN parameters, dynamically. BPANN is trained by using the (known) geoid undulations of the reference points. The geoid undulations of the validation points are estimated via trained BPANN for the controlling process.

In polynomial interpolation approach, the geoid surface of the study area is generated on the basis of the known ellipsoidal and orthometric heights of the reference points by Surfer $12^{\circledR}$ mapping and modelling software. In accordance with the concerns specified in the LSMMIPR, $3^{\text {rd }}$-degree (cubic) polynomial:

$$
\begin{aligned}
& N(Y, X)=A_{0}+A_{1} Y+A_{2} X+A_{3} Y^{2}+A_{4} Y X+ \\
& +A_{5} X^{2}+A_{6} Y^{2}+A_{7} Y^{2} X+A_{8} Y X^{2}+A_{9} X^{3}
\end{aligned}
$$

is used for the geoid undulations of the reference points. The polynomial coefficients are determined according to LSA method. The geoid undulations of the validation points were calculated from this (reference) geoid surface model.

The geoid undulations of the test points are computed via the trained BPANN and the cubic polynomial method in order to evaluate the accuracy of ANN and interpolation approaches.

\section{Results and conclusions}

The statistical values of the geoid undulation discrepancies related to the training, validation, and test datasets are given in Tab. 3, and the geoid undulation discrepancy RMSEs of these points based on BPANN and polynomial interpolation are shown together in Fig. 4.

The values denoted by a superscript $\left(^{*}\right)$ in Tab. 3 are determined for only 11 points of the test dataset. 6 points of the test dataset are outside of the geodetic network 
constituted by the reference points. Polynomial interpolation is inadequate when extrapolating the data beyond the reference dataset.

Table 3 The statistics of the geoid undulation discrepancies (units in $\mathrm{m}$ )

\begin{tabular}{|c|c|c|c|c|}
\hline & & Training & Validation & Test \\
\hline \multirow{4}{*}{$\frac{Z}{\text { Z }}$} & Minimum & $-0,032$ & $-0,261$ & $-0,321$ \\
\hline & Maximum & 0,036 & 0,351 & 0,442 \\
\hline & Mean & 0,000 & 0,011 & 0,013 \\
\hline & RMSE & 0,013 & 0,105 & 0,183 \\
\hline \multirow{4}{*}{$\begin{array}{l}\stackrel{\dot{\Xi}}{\Xi} \\
\dot{0} \\
\stackrel{0}{0}\end{array}$} & Minimum & $-0,587$ & $-0,506$ & $-0,373^{*}$ \\
\hline & Maximum & 0,710 & 0,368 & $0,578^{*}$ \\
\hline & Mean & 0,000 & $-0,018$ & $0,060^{*}$ \\
\hline & RMSE & 0,229 & 0,254 & $0,272^{*}$ \\
\hline
\end{tabular}

The RMSE analysis given in Fig. 4 displays that the training, validation, and test datasets are identical. The differences between the RMSEs of the datasets are reasonably small. It can be regarded as the training dataset is representative of the test area.

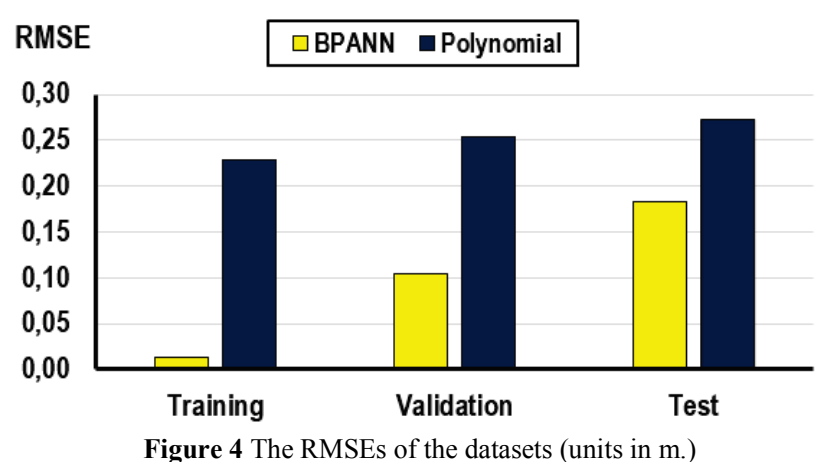

When the results given in Tab. 3 are analysed, it can be considered from Fig. 4 that BPANN estimated geoid undulations more accurate in the test area (for all datasets) with respect to polynomial interpolation, in terms of RMSE.

The objective of this study was to investigate the utility of ANN as a height transformation tool. Based on the experimental results of this paper, the following conclusions can be drawn:

(1) The employment of ANN can be used as an alternative height transformation tool when it is compared to the traditional interpolation methods, in practice. In terms of RMSE, BPANN estimated the geoid undulation as a transformation parameter with a better accuracy in accordance with the polynomial interpolation. The significant feature of BPANN is free-model estimation that interpolation methods cannot be applied.

(2) The properly ANN can be adopted effectively to the transformation between ellipsoidal and orthometric heights while polynomial interpolation (and most of the interpolation methods) is inefficient at the validation/test points requiring extrapolation.

(3) The combination of ANNs (with diverse architecture) as a corrector surface estimator with interpolation methods would be a captivating tool for height transformation in terms of accuracy, due to ANN's qualification that 'learning by example' displaces 'programming'.

ANN is a data-driven approach that the model can be trained by input-output data to determine the parameters of the model. For ANN, there is no requirement to integrate any presumptions about the data frequency distribution. Furthermore, ANN can always be improved by new data to acquire better results. From this perspective, ANN outperforms the traditional interpolation methods and can be utilized as an effective surface approximation tool in height transformation problems. The results of this study reflect that the application of ANN has the potential for transforming ellipsoidal heights to orthometric heights. Despite the feasibility of ANN for height transformation, future research should give further attention to improving extrapolation capability and maintaining robust models.

\section{References}

[1] Helmert, F. R. Die Mathematischen und Physikalischen Theorieen der Höheren Geodäsie (Mathematical and Physical Theories of Higher Geodesy). Druck und Verlag von B. G. Teubner, Leipzig, 1880 .

[2] Pearlman, M.; Altamimi, Z.; Beck, N.; Forsberg, R.; Gurtner, W.; Kenyon, S.; Behrend, D.; Lemoine, F. G.; Ma, C.; Noll, C. E.; Pavlis, E. C.; Malkin, Z.; Moore, A. W.; Webb, F. H.; Neilan, R. E.; Ries, J. C.; Rothacher, M.; Willis, P. Global Geodetic Observing Systemconsiderations for the geodetic network infrastructure. // Geomatica. 60, 22006, pp. 193-204.

[3] Vanícek, P.; Krakiwsky, E. J. Geodesy: The Concepts, $2^{\text {nd }}$ edition. North-Holland, Amsterdam, 1986.

[4] Heiskanen, W. A.; Moritz, H. Physical Geodesy.W.H. Freeman, San Francisco, 1967.

[5] Torge, W. Geodesy, $3^{\text {rd }}$ edition. Walter de Gruyter, Berlin, 2001. DOI: 10.1515/9783110879957

[6] Tenzer, R.; Vanicek, P.; Santos, M.; Featherstone, W. E.; Kuhn, M. The rigorous determination of orthometric heights. // Journal of Geodesy. 79, 1-3(2005), pp. 82-92. DOI: 10.1007/s00190-005-0445-2

[7] Meyer, T. H.; Roman, D. R.; Zilkoski, D. B. What does height really mean? Part IV: GPS orthometric heighting. // Surveying and Land Information Science. 66, 32006, pp. 165-183.

[8] Turkish Chamber of Survey and Cadastre Engineers. Large Scale Map and Map Information Production Regulation (in Turkish). Iskur Press, Ankara, 2008.

[9] Kuhar, M.; Stopar, B.; Turk, G.; Ambrozic, T. The use of artificial neural network in geoid surface approximation. // AVN. 1, (2001), pp. 22-27.

[10] Uzun, S.; Cakir, L. The reliability of surface fitting methods in orthometric height determination from GPS observations. Shaping the Change, XXIII FIG Congress, Munich, Germany, October 8-13, 2006.

[11] Gucek, M.; Basic, T. Height transformation models from ellipsoidal into the normal orthometric height system for the territory of the city of Zagreb. // Studia Geophysica et Geodaetica. 53, (2009), pp. 17-38. DOI: 10.1007/s11200-0090002-1

[12] Erol, B. An automated height transformation using precise geoid models. // Scientific Research and Essays. 6, 6(2011), pp. 1351-1363.

[13] Neuner, H. Modelling deformations of a lock by means of artificial neural Networks. // In: Reiterer, A., Egly, U., Heinert, M. and Riedel, B. (Eds.), Proceedings of the 2nd International Workshop on Application of Artificial Intelligence in Engineering Geodesy, Braunschweig, Germany, 2010, pp. 32-41.

[14] Gullu, M.; Yilmaz, I. Outlier detection for geodetic nets using ADALINE learning algorithm. // Scientific Research and Essays. 5, 5(2010), pp. 440-447. 
[15] Lei, Q.; Lei, L.; Zemin, W. An tropospheric delay model for GPS net RTK. // Proceedings of the $2^{\text {nd }}$ International Conference on Information Technology and Computer Science, 2010, pp. 98-101. DOI: 10.1109/itcs. 2010.30

[16] Gullu, M. Coordinate transformation by radial basis function neural network. // Scientific Research and Essays. 5, 20(2010), pp. 3141-3146.

[17] Turgut, B. A back-propagation artificial neural network approach for three-dimensional coordinate transformation. // Scientific Research and Essays. 5, 21(2010), pp. 33303335.

[18] Gullu, M.; Yilmaz, M.; Yilmaz, I. Application of back propagation artificial neural network for modelling local GPS/levelling geoid undulations: a comparative study. FIG Working Week 2011, Marrakech, Morocco, 18-22 May 2011.

[19] Yilmaz, I.; Gullu, M. Georeferencing of historical maps using back propagation artificial neural network. // Experimental Techniques. 36, 5(2012), pp. 15-19. DOI: 10.1111/j.1747-1567.2010.00694.x

[20] Liao, D.; Wang, Q.; Zhou Y.; Liao, X.; Huang, C. Longterm prediction of the Earth orientation parameters by the artificial neural network technique. // Journal of Geodynamics. $\quad 62, \quad(2012), \quad$ pp. 87-92. DOl: 10.1016/j.jog.2011.12.004

[21] Yilmaz, M.; Gullu, M. A comparative study for the estimation of geodetic point velocity by artificial neural networks. // Journal of Earth System Sciences. 123, 4(2014), pp. 791-808. DOI: 10.1007/s12040-014-0411-6

[22] Yilmaz, M. The utility of artificial neural networks in geodetic point velocity estimation. // Ph.D. Thesis (in Turkish), Afyon Kocatepe University, Afyonkarahisar, 2012.

[23] Rumelhart, D. E.; Hinton, G. E.; Williams, R. J. Learning internal representations by error propagation. In: Rumelhart, D. E.; McClelland, J.; Group, P. R. (Eds.), Parallel Distributed Processing, Vol. 1, MIT Press, Cambridge, 1987.

[24] Leandro, R. F.; Santos, M. C. A neural network approach for regional vertical total electron content modelling. // Studia Geophysica et Geodaetica. 51, 2(2007), pp. 279292. DOI: $10.1007 / \mathrm{s} 11200-007-0015-6$

[25] Valach, F.; Hejda, P.; Bochnick, J. Geoeffectiveness of XRA events associated with RSP II and/or RSP IV estimated using the artificial neural network. // Studia Geophysica et Geodaetica. 51, 4(2007), pp. 551-562.

[26] Beale, M. H.; Hagan, M. T.; Demuth, H. B. Neural Network Toolbox 7 Users Guide. The MathWorks Inc., Natick, 2010

[27] Kavzoglu, T.; Saka, M. H. Modelling local GPS/levelling geoid undulations using artificial neural networks. // Journal of Geodesy. 78, 9(2005), pp. 520-527. DOl: $10.1007 / \mathrm{s} 00190-004-0420-3$

[28] General Command of Mapping. Turkish National Fundamental GPS Network. 2014. URL: http://www.hgk.msb.gov.tr/english/u-10-turkish-nationalfundamental-gps-network.html (09.11.2015)

[29] General Command of Mapping. Turkish National Vertical Control Network. $2014 . \quad$ URL: http://www.hgk.msb.gov.tr/english/u-7-turkish-nationalvertical-control-network--tudka-.html (09.11.2015)

[30] Gullu, M.; Yilmaz, I.; Yilmaz, M.; Turgut, B. An alternative method for estimating densification point velocity based on back propagation artificial neural networks. // Studia Geophysica et Geodaetica. 55, 1(2011), pp. 73-86. DOI: 10.1007/s11200-011-0005-6

[31] Erdogan, S. Modelling the spatial distribution of DEM error with geographically weighted regression: an experimental study. // Computers \& Geosciences. 36, 1(2010), pp. 34-43.
[32] Schroeder, M.; Cornford, D.; Nabney, I. T. Data visualisation and exploration with prior knowledge. In: Palmer-Brown, D.; Draganova, C.; Pimenidis, E.; Mouratidis, H. (Eds.), Engineering Applications of Neural Networks, Springer, Berlin, 2009. DOI: 10.1007/978-3-64203969-0_13

\section{Authors' addresses}

Mustafa Yilmaz, Assoc. Prof. Dr.

Afyon Kocatepe University,

Faculty of Engineering,

Department of Geomatics Engineering

ANS Campus, TR-03200

mustafayilmaz@aku.edu.tr

Bayram Turgut, Assoc. Prof. Dr.

Afyon Kocatepe University,

Faculty of Engineering,

Department of Geomatics Engineering

ANS Campus, TR-03200

bturgut@aku.edu.tr

Mevlut Gullu, Assoc. Prof. Dr.

Afyon Kocatepe University,

Faculty of Engineering,

Department of Geomatics Engineering

ANS Campus, TR-03200

mgullu@aku.edu.tr

Ibrahim Yilmaz, Assoc. Prof. Dr.

Afyon Kocatepe University,

Faculty of Engineering,

Department of Geomatics Engineering

ANS Campus, TR-03200

iyilmaz@aku.edu.tr 